\title{
Copyright Reform and Necessary Flexibilities
}

\author{
Guido Westkamp
}

Published online: 10 July 2014

(C) Max Planck Institute for Innovation and Competition, Munich 2014

There exists widespread criticism concerning the currently foreseen reform of the 2001 Copyright Directive. The European Commission had, amongst other initiatives, invited a range of stakeholders as part of the "Licensing for Europe" initiative; ${ }^{1}$ however, some stakeholders, including library and archive associations, have recently withdrawn from the negotiations, patently articulating concerns that the consultations had concentrated primarily on the issue of licenses, rather than on whether limitations should be strengthened. The departure of these stakeholders illustrates that more is required than negotiating payment terms - a complete rethinking and reform of the Directive based on a fundamental concept permitting an evolution of copyright law commensurate with the rapid advances in technology and, thereby, the ever-changing needs to recognise interests in competition and access to works.

In fact, the Directive itself was very arguably modelled on a vision that strengthening existing rights would facilitate the creation of online business models. The drafters of the Directive certainly had in mind that existing right holders should be offered strong protection in order to incentivise models for the digital dissemination of works, and here clearly the (then) concerns of the music and film industries played a vital role in shaping the normative hierarchy underscoring the Directive's spirit. This is clearly visible in both the Recitals, which caution Member States to keep digital limitations restrictive, and also in the Directive's main part where right holders enjoy unprecedented exclusive rights - including a broad right of reproduction that covers temporary copies and a similarly extensive

\footnotetext{
1 See on text and data mining, the Statement of Commitment by publishers at http://ec.europa.eu/ licences-for-europe-dialogue/sites/licences-for-europe-dialogue/files/10-Text-data-mining.pdf.
}

G. Westkamp $(\bowtie)$

LL.M.; Professor, Dr.; Co-Director, Queen Mary Intellectual Property Research

Institute Centre for Commercial Law Studies

Queen Mary University of London, London, UK

e-mail: g.westkamp@qmul.ac.uk 
right of communication to the public, and in addition the general exclusion of limitations vis-a-vis applied technological protection measures, especially as regards online services.

Conversely, institutions such as libraries and archives, but also schools and universities, face incredible difficulties and legal uncertainties as regards the use of works. The only exception is Art. 5(3)(a), which indeed allows a generous use of works for purposes of illustrating teaching; yet even here Member States have, mainly, chosen not to fully utilise the flexibility offered and have instead opted for, sometimes, rather restrictive educational limitations or maintain a system of licensing where educational institutions are required to obtain permissions from collective management organisations. In some jurisdictions, such as Germany and Austria, educational uses have fared better, both in terms of scope and ease of access. In Austria, for example, an agreement has been reached under which the state actually pays for such uses; in Germany, educational uses in schools are similarly subject to a broader statutory license. But overall, access to digitised works remains difficult, and naturally so as regards any attempt to obtain permission to use works which is subject to licensing in other Member States.

Concurrently, the use of works in archives or libraries remains restrictive: digital technology, of course, permits the use of libraries and archives (and related institutions) to offer access to their holdings precisely for the benefit of institutions such as schools and universities. It would be a tremendous advantage if, for instance, a school or university was provided with a choice of institutions, at home or abroad, who could offer access on the basis of individual licenses, much in the same way as today music and films are disseminated online. The key for establishing such models lies in rethinking how the state allocates, ultimately, the advantages of digital technology. At this juncture, the dual nature of copyright limitations comes to light: first, in a more traditional sense, as norms providing an exception supported by a particular public policy interest; but second as a normative mechanism creating competition between the various interest groups that today influence, to varying degrees, the copyright debate: authors, right holders, service providers, archives and libraries, and institutional or private end users.

Clearly, exceedingly complex obstacles remain. These obstacles emerge both from (international and European) copyright law-making as well as from the complexities of facilitating some consensus between the various interest groups. International copyright law, especially as regards the rights of producers, has incrementally added rights to the existing canon; an example concerns the right of music producers to claim payment for any act of communication under the Rome Convention, a provision criticised at the time of its inception by authors, and which today may be utilised as a belligerent blueprint and, indeed, practical obstacle, against strengthening limitations for the benefit of libraries, archives and educational institutions wishing to ease access to their holdings for the benefit of educational, scientific and other relevant purposes. As regards online dissemination, obtaining licenses for music download or streaming services still requires, partly, individual negotiations with producers, rather than a more effortless access via collective management organisations - a situation that certainly reduces the availability of online services by and large by facilitating monopolistic structures. 
To those one may add the restrictive interpretation of copyright limitations and exceptions as favoured by the Court of Justice, which leaves little scope for rethinking copyright limitations as legal tools permitting competition.

The example of "coupling" libraries or archives (which currently remain constrained to reproductions) on the one hand and educational institutions on the other - certainly something highly desirable from the perspective of offering access to culture for educational purposes - exposes that the Directive is in urgent need of a thorough reform. However, such reform cannot consist in a spurious, patchy or incremental reworking of existing provisions with a view to retain licensing conditions as much as possible. Ultimately, there needs to be some understanding on the rationale of copyright vis-a-vis a multitude of divergent interests and modalities of use. Any reform must clarify that copyright protection does not simply exist to create additional income for existing right holders. It must, on the contrary, provide a doctrinally sound foundation that allows courts in particular to develop copyright alongside ever increasing digital possibilities. In fact, what is required is a principled standard that would permit courts to individually balance, rather than being confronted with a statutory text that is solely informed by vesting rights in existing right holders. The exhaustion doctrine - historically - may indeed provide a fundamental insight: Josef Kohler, who invented the doctrine in the nineteenth century, clearly posited that any intellectual property right becomes restrained once the protected article had been put into circulation for payment. In other words, Kohler was concerned with a fundamental distinction between a market in which right holders could claim a legitimate interest and after markets where they could not, for reasons of an overriding public interest. Of course, this broad reading of the exhaustion rule has vanished over time especially when it came to be applied predominantly in the context of the free movement of goods, but certainly it remains a doctrine that sheds much light on the difficulties faced today. The insight that any prerogative associated with copyright ends where the public interest begins might form a general and doctrinally persuasive foundation for digital copyright, and can function accordingly to similarly support a broader notion of copyright limitations as a mechanism enabling courts to allocate, ultimately, markets - and it should be borne in mind that it was not existing right holders who invested in or created those markets. The legislator may free up markets to allow those access who have, in the past, been labelled as mere institutional users, and may do so with or without a requirement for compensation paid to producers. Such advance would be welcome and could, technically, be implemented via a general fair use clause added to a more detailed enumeration of limitations. Indeed, experience has shown that the rigid partiality which is embedded in the Directive does not permit a meaningful evolution of the law, a fact evident in the range of current Commission initiatives. Whether all this is feasible remains, of course, an entirely different matter. 